\title{
ACUTE CHILDHOOD MORBIDITIES IN RURAL WARDHA: SOME EPIDEMIOLOGICAL CORRELATES AND HEALTH CARE SEEKING
}

\author{
P. R. DESHMUKH, A. R. DONGRE, N. SINHA, B. S. GARG
}

\section{ABSTRACT}

BACKGROUND: In India, common morbidities among children under 3 years of age are fever, acute respiratory infections, diarrhea. Effective early management at the home level and health care-seeking behavior in case of appearance of danger signs are key strategies to prevent the occurrence of severe and life-threatening complications. OBJECTIVES: To find out the prevalence of acute child morbidities, their determinants and health-seeking behavior of the mothers of these children. SETING AND DESIGN: The cross-sectional study was carried out in Wardha district of central India. MATERIAL AND METHODS: We interviewed 990 mothers of children below 3 years of age using 30-cluster sampling method. Nutritional status was defined by National Center for Health Statistics (NCHS) reference. Composite index of anthropometric failure (CIAF) was constructed. Hemoglobin concentration in each child was estimated using the 'filter paper cyanm ethemoglobin method.' Using World Health O rganization guidelines, anemia was defined as hemoglobin concentration less than $110 \mathrm{~g} / \mathrm{L}$. Post-survey focus group discussions (FGDs) were undertaken to bridge gaps in information obtained from the survey. STATISTICAL ANALYSIS: The data was analyzed by using SPSS 12.0.1 software package. Chi-square was used to test the association, while odds ratios were calculated to measure the strength of association. Multiple logistic regression analysis was applied to derive the final model. RESULTS: Anemia was detected in $80.3 \%$ of children, and $59.6 \%$ of children were undernourished as indicated by CIAF. The overall prevalence of acute morbidity was $59.9 \%$. Children with mild anemia, moderate anemia and severe anemia had 1.52, 1.61 and 9.21 times higher risk of being morbid, respectively. Similarly, children with single, 2 and 3 anthropometric failures had $1.16,1.29$ and 2.27 times higher risk of being morbid, respectively. O ut of 594 $(60 \%)$ children with at least one of the acute morbidities, 520 (87.5\%) sought health care, where majority (66.1\%) received treatment from private clinics. The final model suggested that anemia and mother's poor educational status are predictors of childhood morbidity. Conclusions: Nutritional anemia and mother's poor educational status are the most important risk factors of acute childhood morbidity. There is need to revitalize existing health care delivery and child health programs in rural India with emphasis on immediate correction of nutritional anemia.

Key words: Anemia, CIAF, diarrhea, dysentery, fever, malnutrition, pneumonia DOI: 10.4103/0019-5359.55886

Dr. Sushila Nayar School of Public Health, Mahatma Gandhi Institute of Medical Sciences, Sewagram, India
Correspondence:

Dr. P. R. Deshmukh

Dr Sushila Nayar School of Public Health, Mahatma Gandhi Institute of Medical Sciences,

Sewagram - 442 102, India. E-mail: prdeshmukh@gmail.com 


\section{INTRODUCTION}

In India, common morbidities among children under 3 years of age are fever, acute respiratory infections, diarrhea..$^{[1]}$ Many of these children die at home, without access to essential health services that might have saved their lives. Some children succumb to respiratory or diarrheal infections that are no longer threats in industrialized countries. ${ }^{[2,3]}$ Up to half of deaths of children under the age of 5 years are associated with undernutrition, a condition in which a young child's body and mind are deprived of the nutrients needed for growth and development. United Nations' millennium development goal is committed to reduce two thirds of child mortality by the year 2015. Integrated Management of Neonatal and Childhood Illnesses (IMNCI) also envisions that family and community health practices, especially health care-seeking behaviors, are to be improved to reduce child morbidity and mortality. ${ }^{[4]}$ Effective early management at the home level and health care-seeking behavior in case of appearance of danger signs are key strategies to prevent occurrence of severe and life-threatening childhood illnesses. ${ }^{[5]}$ Understanding the determinants of these morbidities, as well as the health seekingbehavior, may help in planning interventions for controlling childhood morbidity and mortality.

Though the magnitude of childhood morbidities in India is well known, very few studies have focused on their determinants and the healthseeking behavior of the mothers of the ill children. ${ }^{[6-8]}$ Hence we conducted the present study to find out the prevalence of acute morbidities; their epidemiological determinants; and the health care-seeking behavior of mothers among children below 3 years of age in rural Wardha district.

\section{MATERIALS AND METHODS}

\section{Study setting}

The present triangulated research study using quantitative (survey) and qualitative (focus group discussions, FGDs) methods was undertaken in 3 primary health centers (PHCs) of Wardha district, namely, Anji, Gaul and Talegaon, with a total population of 88,187 . A list of 5067 children was prepared by undertaking house-to-house visits. The study site was located in rural Wardha district, about $758 \mathrm{~km}$ east of the Maharashtra state capital, Mumbai. The health care delivery system of the district comprised of state-owned subcenters (SCs), primary health centers (PHCs) at the primary level; rural hospital $(\mathrm{RH})$ at the secondary level; and district hospital (DH) and 2 private medical colleges at the tertiary level. Apart from this structure, there were private doctors, practicing allopathy and/ or Indian systems of medicine. The study was approved by the institutional ethical committee.

\section{Study design, sampling method and sample size}

The present study was conducted in 2 phases. The first phase comprised of quantitative survey. The second phase comprised of postsurvey qualitative study (FGDs) to bridge identified gaps in the information obtained from survey. ${ }^{[9]}$ The study was undertaken during the period from January 2005 to December 2005.

Considering the rough estimate of the proportion of children below 3 years of age who could have one or the other acute morbidity 
under study to be $0.5 ; 5 \%$ alpha error; $10 \%$ relative error in the estimated prevalence; and design effect of 2.5, the minimum sample size required was 960 children. ${ }^{[10]}$ The sample was drawn from $3 \mathrm{PHC}$ areas by 30 -cluster sampling technique, where the number of clusters was proportional to the population in each of the 3 PHC areas. From each cluster, 33 children below 3 years of age ( 11 children from each of the following age groups: 0-11 months, 12-23 months and 24-35 months) were chosen by systematic randomization. Thus the total sample studied comprised of 990 children. The study was approved by the institutional ethical committee.

\section{Data collection}

After obtaining informed consent, a trained interviewer interviewed 990 mothers of children below 3 years of age using a pre-designed and pre-tested questionnaire by undertaking houseto-house visits. The structured questionnaire covered symptom-specific information on acute child morbidities as perceived by the mother in the 2 weeks preceding the survey, as well as health care-seeking behavior of mothers of these children. Socioeconomic status was assessed by the type of ration card issued to the family of the child by the government of Maharashtra state under its public distribution system. Families below poverty line receive yellow ration cards, while other families receive orange ration cards. Health care seeking was defined as any attempt by the mother to obtain an expert opinion from a biomedical health care provider outside the home during the child's illness.

To assess nutritional status, weight was obtained by Salter scale provided by United
Nations Children's Fund (UNICEF) . Height was measured for children between 24 and 35 months, while length was measured for children below 24 months as per the WHO guidelines on anthropometry. ${ }^{[11]}$

Hemoglobin concentration in children between 6 and 35 months ( $n=772$ ) was estimated using 'filter paper cyanmethemoglobin method.' ${ }^{\text {[12] }}$ Using WHO guidelines, anemia was defined as hemoglobin concentration less than $110 \mathrm{~g} / \mathrm{L} .{ }^{[13]}$ Mild anemia was defined as hemoglobin concentration less than $110 \mathrm{~g} / \mathrm{L}$ but greater than or equal to $100 \mathrm{~g} / \mathrm{L}$; moderate anemia, as hemoglobin concentration less than $100 \mathrm{~g} / \mathrm{L}$ but greater than or equal to $70 \mathrm{~g} / \mathrm{L}$; and severe anemia, as hemoglobin concentration less than $70 \mathrm{~g} / \mathrm{L} .{ }^{[14,15]}$

\section{Post-survey qualitative study}

Post-survey focus group discussions (FGDs) were undertaken to bridge gaps in the information obtained from the survey. ${ }^{[9]} A$ trained social worker, after obtaining informed consent, facilitated FGDs with the mothers of children below 3 years of age belonging to different socioeconomic groups. The structured guidelines were followed, and a note taker carefully recorded the discussions in the local language, Marathi. A total of 9 FGDs were conducted. The number of FGDs to be undertaken was decided by the saturation point, i.e., the point at which it stopped yielding any new information.

\section{Statistical analysis}

The data was analyzed by using SPSS 12.0.1 software package. Nutritional status was defined by NCHS reference (1978) values for 'weight for age,' 'weight for height' and 'height for age.' 'Weight for age,' 'weight for height' 
and 'height for age' values below 2 standard deviations were considered as underweight, wasted and stunted. ${ }^{[11]}$ For nutritional analysis, epi_info 6.04d was used.

We constructed the composite index of anthropometric failure (CIAF) as explained by Nandy et al. ${ }^{[16]}$ As given by Nandy et al., the anthropometric permutations of the children are as follows: group A- no failure; group B- wasting only; group C- wasting and underweight; group D- wasting, stunting and underweight; group E- stunting and underweight; group F- stunting only; and finally, group $\mathrm{Y}$ - underweight only. The sum of the numbers of children in groups $\mathrm{B}$ to $\mathrm{F}$ provides the CIAF. ${ }^{[16]}$ These were further grouped as having 'no failure,' 'single failure,' i.e., groups B, F and Y; 'two failures,' i.e., groups $C$ and E; and 'three failures,' i.e., group D; for analysis purpose.

Associations between risk factors and morbidity were evaluated by using chi-square tests. To calculate odds ratio (OR), morbidity was taken as a dependent variable with dichotomous outcome (yes, no); while age group (0-11, 1223, 24-35 months), sex (male, female), caste [(open category and other categories ('other backward castes,' scheduled castes, scheduled tribes)], mother's education ( $>10$ years, 1-10 years, uneducated), family type (joint, nuclear), socioeconomic status (above poverty level, below poverty level), anemia (no anemia, mild anemia, moderate anemia, severe anemia) and CIAF (no failure, single failure, two failures, three failures) were considered independent variables. Independent variables with a $P$ value of .2 and less in bivariate analysis were forced into the final model that was derived by multiple logistic regressions using backward LR method.
$P<.05$ was taken as a cut off value of statistical significance. A content analysis of qualitative data was undertaken.

\section{RESULTS}

\section{Study population}

Out of the 990 children studied, there were 330 children in each of the following age groups: 0-11 months, 12-23 months and 24-35 months; and $55.1 \%$ were male. A majority $(51.4 \%)$ of children were from the 'other backward castes' category, while only $2.9 \%$ were from the 'open' caste category. Majority (65.2\%) of mothers had $1-10$ years of education, while $6.9 \%$ of mothers were uneducated. About $57.5 \%$ of children were from a joint family, and $19.9 \%$ of children were from families below poverty level [Table 1]. About 137 (85.1\%) out of 161 children below 6 months were exclusively breastfed during the last 24 hours.

The prevalence of anemia was $80.3 \%$. Mild, moderate and severe anemias were detected in $27.7 \%, 51.3 \%$ and $1.3 \%$ of children, respectively. As per composite index of anthropometric failure (CIAF), $59.6 \%$ of children were undernourished, where $22.4 \%$ of children had only 1 type of anthropometric failure (2.4\%only wasting; $7.4 \%$ - only underweight; and $12.6 \%$ - only stunting), $32.0 \%$ of children had 2 types of anthropometric failures (6.2\%- wasting and underweight; and $25.8 \%$ - stunting and underweight) and $5.2 \%$ of children had 3 types of anthropometric failures (stunting, wasting and underweight) [Table 1].

\section{Acute morbidities}

The overall prevalence of acute morbidity was $59.9 \%$, i.e., at least one of the conditions like 
Table 1: Characteristics of the study subjects and prevalence of morbidity by characteristics

\begin{tabular}{|c|c|c|c|}
\hline Variable & Total & $\begin{array}{c}\text { Any } \\
\text { morbidity } \\
\text { Number } \\
\text { (\%) }\end{array}$ & $\begin{array}{c}P \text { value } \\
\text { Number } \\
(\%)\end{array}$ \\
\hline Overall & $990(100.0)$ & $593(59.9)$ & - \\
\hline \multicolumn{4}{|l|}{ Age group (months) } \\
\hline $0-11$ & 330 (33.3) & $179(54.2)$ & 0.010 \\
\hline $12-23$ & 330 (33.3) & $217(65.8)$ & \\
\hline 24-35 & 330 (33.3) & $197(59.7)$ & \\
\hline \multicolumn{4}{|l|}{ Sex } \\
\hline Male & $545(55.1)$ & $331(60.7)$ & 0.558 \\
\hline Female & 445 (44.9) & $262(58.9)$ & \\
\hline \multicolumn{4}{|l|}{ Caste } \\
\hline Open & $29(2.9)$ & $14(48.3)$ & 0.373 \\
\hline Other backward castes & $509(51.4)$ & $298(58.5)$ & \\
\hline Scheduled castes & $209(21.1)$ & $128(61.2)$ & \\
\hline Scheduled tribes & $243(24.6)$ & $153(63.0)$ & \\
\hline \multicolumn{4}{|l|}{ Mother's education } \\
\hline More than 10 years & $276(27.9)$ & $143(51.8)$ & 0.040 \\
\hline $1-10$ years & $645(65.2)$ & $409(63.4)$ & \\
\hline Uneducated & $69(6.9)$ & $41(59.4)$ & \\
\hline \multicolumn{4}{|l|}{ Family Type } \\
\hline Joint & $569(57.5)$ & $340(59.8)$ & 0.914 \\
\hline Nuclear & $421(42.5)$ & $253(60.1)$ & \\
\hline \multicolumn{4}{|l|}{ Socioeconomic status } \\
\hline Above poverty level & $793(80.1)$ & $479(60.4)$ & 0.517 \\
\hline Below poverty level & $197(19.9)$ & $114(57.4)$ & \\
\hline \multicolumn{4}{|l|}{ Anemia $(n=772)^{\star}$} \\
\hline No anemia & $242(24.9)$ & $126(52.1)$ & 0.003 \\
\hline Mild anemia & $255(26.2)$ & $159(62.4)$ & \\
\hline Moderate anemia & $465(47.8)$ & $296(63.7)$ & \\
\hline Severe anemia & $11(1.1)$ & $10(90.9)$ & \\
\hline \multicolumn{4}{|l|}{$\operatorname{CIAF}(n=978)^{\star \star}$} \\
\hline No failure & 389(39.3) & $219(56.3)$ & 0.060 \\
\hline 1 failure & $222(22.4)$ & $133(59.9)$ & \\
\hline 2 failures & $316(32.0)$ & $197(62.3)$ & \\
\hline 3 failures & $51(5.2)$ & $38(74.5)$ & \\
\hline
\end{tabular}

${ }^{*}$ Hemoglobin in children below 6 months of age was not estimated, ${ }^{* *} \mathrm{SD}$ scores for 12 children were beyond the acceptable limits, hence omitted

fever, cough and cold, pneumonia, diarrhea or dysentery was present during the 2 weeks preceding the survey. Most frequently reported symptoms were cough and cold (41\%) and fever $(34.1 \%)$, followed by pneumonia (6.7\%), diarrhea (5.7\%) and dysentery (0.3\%) [Table 2].

The prevalence of morbidity was minimum $(54.2 \%)$ in the first year of life, while it was maximum $(65.8 \%)$ in the second year of life. The difference in the prevalence of morbidities among children of different age groups was statistically significant $(P<0.05)$. It did not differ significantly between male $(60.7 \%)$ and female $(58.9 \%)$ children $(P>$ 0.05). It was least (48.3\%) among open caste category children and highest (63.0\%) among scheduled tribe children, but the difference in the prevalence of morbidities between different caste groups was not statistically significant $(P>0.05)$. The prevalence of morbidities among children with mothers with education of 10 years or more was $51.8 \%$ as compared to $63.4 \%$ and $59.4 \%$ among children with mothers with less education or no education, respectively $(P<0.05)$. Acute morbidities were not found to be significantly associated with type of family and socioeconomic status. These were associated significantly with grades of anemia. The maximum (90.9\%) prevalence of morbidities was found in children with severe anemia. It was $63.7 \%, 62.4 \%$ and $52.1 \%$ among children with moderate, mild and no anemia, respectively $(P<0.05)$. No significant association was found between the number of anthropometric failures and the morbidities [Table 1].

\section{Some epidemiologic correlates}

Children aged 12-23 months were 1.62 times more likely to be morbid as compared with children aged 0-11 months. This risk decreases to 1.25 times in the age group 24-35 months. Similarly, the risk of being morbid was 1.61 and 1.36 times among children with mothers having 1-10 years of education and with mothers having no education, respectively, as compared to that among those children with mothers having more than 10 years of education. Children with mild anemia, moderate anemia and severe anemia had 1.52, 1.61 and 9.21 times higher risk of being morbid, 
Table 2: Some epidemiologic correlates of morbidity

\begin{tabular}{|c|c|c|c|c|}
\hline Variable & Odds ratio & $\begin{array}{c}\text { Unadjusted } \\
95 \% \mathrm{Cl}\end{array}$ & $\begin{array}{c}\text { Final Model@ } \\
\text { Odds ratio }\end{array}$ & $95 \% \mathrm{Cl}$ \\
\hline \multicolumn{5}{|l|}{ Age group (months) } \\
\hline $0-11$ & 1 & & & \\
\hline $12-23$ & 1.62 & $(1.16-2.22)$ & & \\
\hline $24-35$ & 1.25 & $(0.91-1.72)$ & & \\
\hline \multicolumn{5}{|l|}{ Sex } \\
\hline Male & 1 & & & \\
\hline Female & 0.93 & $(0.72-1.20)$ & & \\
\hline \multicolumn{5}{|l|}{ Caste } \\
\hline Open & 1 & & & \\
\hline Other backward castes & 1.51 & $(0.67-3.40)$ & & \\
\hline Scheduled castes & 1.69 & $(0.73-3.95)$ & & \\
\hline Scheduled tribes & 1.82 & $(0.74-4.22)$ & & \\
\hline \multicolumn{5}{|l|}{ Mother's education } \\
\hline More than 10 years & 1 & & 1 & \\
\hline $1-10$ years & 1.61 & $(1.20-2.17)$ & 1.44 & $1.07-1.94$ \\
\hline Uneducated & 1.36 & $(0.77-2.41)$ & 1.10 & $0.64-1.90$ \\
\hline \multicolumn{5}{|l|}{ Family Type } \\
\hline Joint & 1 & & & \\
\hline Nuclear & 1.01 & $(0.78-1.31)$ & & \\
\hline \multicolumn{5}{|l|}{ Socioeconomic status } \\
\hline Above poverty level & 1 & & & \\
\hline Below poverty level & 0.90 & $(0.66-1.24)$ & & \\
\hline \multicolumn{5}{|l|}{ Anemia $(n=772)^{*}$} \\
\hline No anemia & 1 & & 1 & \\
\hline Mild anemia & 1.52 & $(1.05-2.22)$ & 1.56 & $1.09-2.23$ \\
\hline Moderate anemia & 1.61 & $(1.16-2.24)$ & 1.57 & 1.14-2.17 \\
\hline Severe anemia & 9.21 & $(1.19-195.17)$ & 8.90 & $1.17-70.83$ \\
\hline \multicolumn{5}{|l|}{$\operatorname{CIAF}(n=978)^{\star *}$} \\
\hline No failure & 1 & & & \\
\hline 1 failure & 1.16 & $(0.82-1.64)$ & & \\
\hline 2 failures & 1.29 & $(0.94-1.76)$ & & \\
\hline 3 failures & 2.27 & (1.13-4.64) & & \\
\hline
\end{tabular}

${ }^{\star}$ Hemoglobin in children below 6 months of age was not estimated, **SD scores for 12 children were beyond the acceptable limits, hence omitted, ${ }^{\circledR}$ Final model was derived by multivariate logistic regression by using backward LR method

respectively. Similarly, children with single, 2 and 3 anthropometric failures had 1.16, 1.29 and 2.27 times higher risk of being morbid, respectively [Table 2]. On bivariate analysis, statistically significant risk of any morbidity (at least one of the morbidities studied) was associated with child's age being 12-23 months, child having mother who was less educated or uneducated, child being anemic and child having all 3 types of anthropometric failures (stunting, wasting and underweight).

After applying a multiple logistic regression, the final model suggested that significant predictors of morbidity were mother's education and anemia. Children with mothers having 1-10 years of education and children of illiterate mothers were at 1.43 (95\% Cl: 1.06-1.93) and 1.10 (95\% Cl: 0.63-1.90) times higher risk of morbidity, respectively, compared with children with mothers having more than 10 years of education. Children with mild anemia, moderate anemia and severe anemia were at 1.56 (95\%Cl: $1.09-2.23), 1.57$ (95\% Cl: 1.14-2.17) and $8.9(95 \% \mathrm{Cl}: 1.17-70.83)$ times higher risk of morbidity, respectively, compared with children with normal hemoglobin levels [Table 2].

\section{Health seeking}

Out of $594(60 \%)$ children with at least one of the acute morbidities, $520(87.5 \%)$ sought health care, where the majority $(66.1 \%)$ received 
treatment from private clinics, followed by rural hospital/ district hospital/ medical college $(21 \%)$ and sub-center/primary health center $(9.2 \%)$. Majority $(66.7 \%)$ of the mothers gave home-based treatment for diarrhea [Table 3]. All the children received home-available fluids, while $61.1 \%$ of children with diarrhea received oral re-hydration solution (ORS).

As explored in the post-survey FGDs with the mothers, the major reason for not accessing government health facilities was lack of faith in government health services due to unavailability of doctors at the primary health care level like SCs/ PHCs, poor care by doctors and nurses at the tertiary care level, lack of medicines and equipments and finally no relief with the treatment provided. The paid services of doctors at private clinics were reported to be good as they were available when required; and unlike government health care providers, private providers treated the case in less time period, without further referring the sick child. So rural people preferred to borrow and spend money for the sick child's treatment.

\section{DISCUSSION}

Children under 3 years of age are very prone to infections and childhood morbidities. Morbidities lead to malnutrition and micro- nutrient deficiencies and vice versa. Acute respiratory infections, primarily pneumonia, are the major cause of illness among children and the leading cause of childhood mortality throughout the world, followed by diarrhea. ${ }^{[15]}$

In the present study, about $60 \%$ of children were reported to have at least one of the acute morbidities like fever, cough and cold, pneumonia, diarrhea and dysentery within the 2 weeks of the survey. Most frequently reported symptoms were cough and cold $(41 \%)$ and fever $(34.1 \%)$, followed by pneumonia $(6.7 \%)$, diarrhea $(5.7 \%)$ and dysentery $(0.3 \%)$. Mishra et al. reported that $26.3 \%$ of children below the age of 5 years suffered from cough and cold; $22 \%$, from diarrhea; and $3.6 \%$, from pneumonia; in rural Allahabad. ${ }^{[17]}$ Ray et al. reported that $58.2 \%$ and $22.2 \%$ of children below the age of 5 years suffered from ARI and diarrhea, respectively, in rural West Bengal. ${ }^{[18]}$ Another study from the rural areas of Meerut district of Uttar Pradesh revealed that $42.3 \%$ of children below the age of 5 years suffered from ARI. ${ }^{[19]}$ According to National Family Health Survey-III (NFHS-III) in India, 19.2\%, $29.5 \%$ and $2.6 \%$ of mothers of children below the age of 3 years reported that their children suffered from diarrhea, fever and dysentery, respectively. ${ }^{[20]}$

Table 3: Acute morbidity pattern and health-seeking behavior during illness

\begin{tabular}{|c|c|c|c|c|c|c|}
\hline $\begin{array}{l}\text { Morbidity } \\
\text { Morbidity } \\
(n=990)\end{array}$ & $\begin{array}{l}\text { Number with } \\
\text { treatment }\end{array}$ & $\begin{array}{c}\text { Number sought } \\
\text { SC/PHC }\end{array}$ & \multicolumn{2}{|c|}{$\begin{array}{c}\text { Source of treatment } \\
\mathrm{CHC} / \mathrm{DH} / \mathrm{MC}\end{array}$} & Private clinic & Home \\
\hline Fever & $338(34.1)$ & $325(96.2)$ & $24(7.4)$ & $72(22.2)$ & $221(68.0)$ & $8(2.5)$ \\
\hline Cough and cold & $406(41.0)$ & $377(92.9)$ & $32(8.5)$ & $74(19.6)$ & $261(69.2)$ & $10(2.7)$ \\
\hline Pneumonia & $66(6.7)$ & $66(100.0)$ & $2(3.0)$ & $12(18.2)$ & $51(77.3)$ & $5(7.6)$ \\
\hline Diarrhea & $57(5.7)$ & $51(89.5)$ & $5(9.8)$ & $5(9.8)$ & $12(23.5)$ & $34(66.7)$ \\
\hline Dysentery & $3(0.3)$ & $3(100.0)$ & 0 & 0 & $3(100.0)$ & 0 \\
\hline $\begin{array}{l}\text { At least one } \\
\text { of the morbidities }\end{array}$ & $594(60.0)$ & $520(87.5)$ & $48(9.2)$ & $109(21.0)$ & $344(66.1)$ & $21(4.0)$ \\
\hline
\end{tabular}

SC- sub-center, PHC- primary health center, CHC- community health center, DH- district hospital, MC- medical college 
In the present study, it is noteworthy that $87.5 \%$ of children from this rural community received health care, where $66.1 \%$ of sick children got treatment from private clinics. Majority of mothers accessed private health care service for all illness symptoms, and it was not restricted to any particular illness symptoms except for diarrhea, where home remedy was sought in the form of home-available fluids and ORS. In NFHS-III, $71 \%$ of children with fever were taken to a health facility, and $26 \%$ of children with diarrhea received ORS. ${ }^{[20]}$ This information showing interstate variations in child morbidity pattern is crucial for needbased and area-specific prioritization and policy formulation during implementation of child survival program.

Owing to the poor quality of treatment provided by government health care providers, the poor rural mothers preferred to spend out-of-pocket and access private health care services. In order to address resource limitations and management inefficiencies of public health facilities, the government of India has undertaken an ambitious nationwide decentralized National Rural Health Mission (NRHM), which intends to implement Integrated Management of Neonatal and Childhood Illnesses (IMNCl) through training and capacitybuilding of the existing health care delivery system. ${ }^{[21]}$ Apart from revitalization of public health care systems, NRHM also envisioned public-private partnership for health care delivery. ${ }^{[21]}$ Poor rural people are expected to benefit from these schemes.

In the present study, out of the various risk factors assessed, mother's poor educational status (1-10 years of education) and presence of nutritional anemia were the factors significantly associated with acute morbidities. Basu and Stephenson also reported the importance of maternal education in prevention of childhood morbidity and mortality. ${ }^{[7]}$ It needs long-term intervention to improve the educational status of mothers. Iron deficiency has an adverse effect on the immune system. Reduced capacity of leucocytes to kill ingested microorganisms and decreased ability of lymphocytes to replicate, coupled with the lower concentration of cells responsible for cell-mediated immunity, result in higher morbidity due to infectious diseases. Iron supplementation has demonstrated reduction in morbidities from infectious diseases. ${ }^{[22]}$ This makes a strong case to 'operationalize' programs like National Nutritional Anemia Control Program and the IMNCI program, which focus on prevention and correction of nutritional anemia among children. The correction of nutritional anemia will break the vicious cycle of morbidity leading to malnutrition and vice versa.

Conventionally, malnutrition is assessed by 'weight for age,' i.e., underweight; 'weight for height,' i.e., wasting; and 'height for age,' i.e., stunting; implicating different processes of malnutrition. Each of these indicators gives different values, and there is overlap between them. There is no summary indicator to show how many children in total are affected by malnutrition. Composite index of anthropometric failure (CIAF) overcomes the above-mentioned drawback of conventional indicators and gives a summary measure of undernutrition. It encompasses wasting and/ or stunting and/ or underweight status. ${ }^{[16]}$ CIAF used in combination with these routinely used indicators will present a better picture 
of malnutrition in the community. ${ }^{[16]}$ Nandy et al. have shown the relationship between the number of anthropometric failures and the morbidities among children. ${ }^{[16]}$ Nandy and Miranda have argued in favor of using the summary measure to track the progress in achievement of millennium development goals. ${ }^{[23]}$ In the present study, significantly higher risk of morbidity was observed in a child who had 3 types of anthropometric failures simultaneously.

To summarize, the study points to a number of constraints in the existing rural health care delivery systems in India and high prevalence of acute childhood morbidities. Nutritional anemia and mother's poor educational status were the most important risk factors of acute childhood morbidity. There is need to revitalize the existing health care delivery systems and child health programs in rural India with emphasis on immediate correction of nutritional anemia. However, the limitation of the study should be kept in mind. The study was carried out in a small geographic area with high female literacy, and the findings should be validated by carrying out studies in larger geographic areas so that the findings can be generalized to larger population groups.

\section{ACKNOWLEDGMENT}

We acknowledge with thanks the financial assistance received from Aga Khan Foundation and USAID under Child Survival Grant with the cooperative agreement GHS-A-00-03-00015-00.

\section{REFERENCES}

1. National Family Health Survey-1998-99. International Institute for Population Sciences,
Mumbai, 2000. Available from: http://www. nfhsindia.org/data/india/indch6.pdf. [cited on 2006 Dec 10].

2. World Health Organization. World Health Report, 2003. Available from: http://www.who.int/ whr/2003/en/whr03_en.pdf. [cited on 2006 Dec 10].

3. United Nations Children Fund. Millennium development goals, 2000. Available from: http:// www.unicef.org/mdg/childmortality.html. [cited on 2009 Jul 13].

4. Government of India, Ministry of Health and Family Welfare. Integrated Management of Neonatal and Childhood illness: Training modules for medical officers. New Delhi: 2005. p. 3.

5. Gupta N, Jain SK, Ratnesh, Chawla U, Hossain $\mathrm{S}$, Venkatesh S. An evaluation of diarrheal diseases and acute respiratory infection control programmes in a Delhi slum. Indian $\mathrm{J}$ Pediatr 2007;74:471-6.

6. Nayar KR. Social exclusion, caste and health: A review based on the social determinants framework. Indian J Med Res 2007;126:355-63.

7. Basu AM, Stephenson R. Low levels of maternal education and the proximate determinants of childhood mortality: A little learning is not a dangerous thing. Soc Sci Med 2005;60:2011-23.

8. Awasthi S, Agarwal S. Determinants of childhood mortality and morbidity in urban slums in India. Indian Pediatr 2003;40:1145-61.

9. Hudelson PM. Qualitative research for health programmes. Geneva: World Health Organization; 1994.

10. Lwanga SK, Lemeshow S. Sample size determination in health studies: A practical manual. Geneva: World Health Organization; 1991. p.2.

11. World Health Organization. Physical status: the use and interpretation of anthropometry. Geneva: World Health Organization; 1995.

12. Raghuramulu N, Nair MK, Kalyansundaram S, editors. A manual of laboratory techniques. $2^{\text {nd }} \mathrm{ed}$. National Institute of Nutrition: Hyderabad; 2003. 

p. 68-9.

13. World Health Organization. Iron deficiency anemia - assessment, prevention and control: A guide for program managers. Geneva: World Health Organization; 2001. p.33.

14. Kapur D, Agarwal KN, Sharma S, Kela K, Kaur I. Iron status of children aged 9-36 months in an urban slum integrated child development services project in Delhi. Indian Pediatr 2002;39:136-44.

15. Murray CJ, Lopez AD. The global burden of disease. Cambridge, Massachusetts: Horward University Press; 1996.

16. Nandy S, Irving M, Gordon D, Subramanian SV, Smith GD. Poverty, child undernutrition and morbidity: New evidence from India. Bull World Health Organ 2005;83:210-6.

17. Mishra PC, Agrawal VK, Baveja R. Immunization status and morbidity pattern of children: A clinical study. Indian Medical Gazette 1998;122:234-6.

18. Ray SK, Haldar A, Biswas B, Misra R, Kumar S. Epidemiology of undernutrition. Indian J Pediatr 2001;68:1025-30.

19. Kaushik PV, Singh JV, Bhatnagar M, Garg SK, Chopra H. Nutritional correlates of acute respiratory infections. Indian J Mat Child Health 1995;6:71-2.

20. National Family Health Survey-2005-06. International Institute for Population Sciences, Mumbai - India and ORC Macro. November 2007. p. 233-40.

21. Ministry of Health and Family Welfare. 2006. National Rural Health Mission document, 20052012, New Delhi. Available from: http://mohfw. nic.in/NRHM/Documents/NRHM\%20Mission\%20 Document.pdf. [cited on 2006 Dec 10].

22. World Health Organization. Iron deficiency anemia - assessment, prevention and control: a guide for program managers. Geneva: World Health Organization; 2001. p. 94.

23. Nandy S, Miranda JJ. Overlooking undernutrition? Using a composite index of anthropometric failure to assess how underweight misses and misleads the assessment of undernutrition in young children. Soc Sci Med 2008;66:1963-6.

Source of Support: Aga Khan Foundation and USAID under Child Survival Grant with the cooperative agreement GHS-A-00-03-00015-00. Conflict of Interest: None declared.

\section{Author Help: Reference checking facility}

The manuscript system (ww w.journalonweb.com) allows the authors to check and verify the accuracy and style of references. The tool checks the references with PubM ed as per a predefined style. Authors are encouraged to use this facility, before submitting articles to the journal.

- The style as well as bibliographic elements should be $100 \%$ accurate, to help get the references verified from the system. Even a single spelling error or addition of issue number/month of publication will lead to an error when verifying the reference.

- $\quad$ Example of a correct style

Sheahan P, O'leary G, Lee G, Fitzgibbon J . Cystic cervical metastases: Incidence and diagnosis using fine needle aspiration biopsy. Otolaryngol Head Neck Surg 2002;127:294-8.

- $\quad$ Only the references from journals indexed in PubMed will be checked.

- $\quad$ Enter each reference in new line, without a serial number.

- Add up to a maximum of 15 references at a time.

- If the reference is correct for its bibliographic elements and punctuations, it will be show $n$ as CORRECT and a link to the correct article in PubM ed will be given.

- If any of the bibliographic elements are missing, incorrect or extra (such as issue number), it will be shown as INCORRECT and link to possible articles in PubM ed will be given. 